\title{
Current methods of treating nasal breathing problems in infants and children
}

\author{
Jacques TALMANT, Joel DENIAUD
}

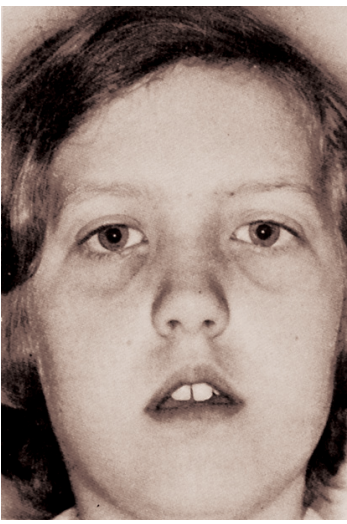

\begin{abstract}
Measurements of nasal resistance do not give an exhaustive functional assessment of nasal breathing function. Nevertheless, an increase in its thermal endocranial exchanges during its operation, which are regulated specifically by respiratory nasal mucosa, can be utilized to construct an operative physiological definition of nasal breathing at a state of optimal rest. These precise assessments, in elucidating the etiology of oral-nasal malformations, can give a clear picture of the morphological characteristics that orthodontists should strive to optimize as the face develops over the course of their treatment of malocclusions.
\end{abstract}

\section{KEYWORDS}

Dentofacial orthopedics

Selective cerebral cooling

Sleep disturbances

Nasal breathing. 
The therapeutic orientation we propose in this article derives from a highly precise etiopathogenic diagnosis of na- sal breathing disturbances, based on a physiological definition of "nasal breathing at a state of optimal rest (ONB)".

\section{1 - WHY DEFINE OPTIMAL NASAL BREATHING (ONB)?}

For some considerable time two issues have been in contention and remain unresolved:

- on the one hand because the complicated process of making a diagnosis of nasal malfunction, which is surely not one for a beginner to confront, has not been entirely clarified, in part because breathing must be considered as an oro-nasal function, with the oral behavior adapting itself to functional nasal capacities;

- and on the other hand no combinations of an exploration of the trajectory of inspired air or the qualities of the parietal response to its passage or the physical parameters measured to calculate nasal resistance provide enough data for an examiner to make an exhaustive functional assessment of nasal breathing. In fact, some observers note the association in the same patient of a normal nasal resistance while the patient has the sensation of a bilateral or unilateral nasal obstruction ${ }^{24}$. An evaluation of nasal breathing based solely on fluid mechanics is, accordingly, insufficient. "Biology has a dimension of complexity that physics does not ${ }^{16}$.

The classical definition of breathing at normal rest, moreover, is so conventional that the mixed mode, oro-nasal, has been proposed as the norm; leaving only the extent of the oral portion of this modality to be established; some ${ }^{25}$ propose an approximate value of $15 \%$, while others $^{40}$ consider that as much as $30 \%$ of the so-called normal population use "use oral breathing up to a certain point".

Briefly stated, establishing a too limited physiological assessment causes some patients with breathing disturbances to see their facial morphogenesis definitely placed at a distance from its possible ideal in an atmosphere of seeming general indifference.

Some clinicians treating malocclusions have been asking themselves whether the frequent histories of otolaryngological problems that so many of their patients suffer from indicate the likelihood that there is a causal relationship between chronic malfunction of nasal breathing at rest and alveolo-dental disharmony, or malocclusion, the ensemble of which would constitute an oro-nasal pathological entity characterized by facial and cranio-cervical adaptations. To verify the pertinence of such a relationship it would be necessary to define the reference modalities of breathing and then to define the precise parameters within which optimum physiological breathing occurs. 
1-1 - The first difficulty: establishing a vocabulary

The improper use of words derived from the Latin verb spirarer, to breathe, to designate the many phenomena associated with breathing makes it worthwhile to review the following definitions:

- respiration: each of the oxidizing actions producing energy. Every living cell respires;

- hematosis: exchange of gases in the lungs that converts venous blood into arterial blood;

- breathing: renewal of air (or of amniotic fluid for the foetus) in the airways.

\section{1 - 2 - The second difficulty: preference for the nasal route}

Why is the healthy nose the preferred route for breathing at rest when the nostrils constitute the narrowest segment of all the airways, presenting a resistance to passage of gases equal to that of all the other elements of the airway complex including those on the periphery of the lungs ${ }^{10}$ when the mouth offers so much less resistance?

For one thing, the nasal fossae function much more subtly than simple rigid tubes whose sole role would be to provide channels for gases to pass through because their very resistance changes their performance. For the force opposing the movement of air is not the only energy expended by nasal breathing. And the definition of optimal nasal breathing must integrate all the effects tied to conditioning of inhaled air in the nasal passages as controlled by the autonomic nervous system that are connected to nasal mucosa but not to oral mucosa even if the targets aimed at are not exclusively bronchoalveolar. This definition accordingly, must integrate all the products of the physiological interaction between the current of inspired air and the nasal mucosa at the air-mucosal interface, which makes this pathway so comfortable at the same time distinguishing it from the oral pathway. It must integrate the influence exerted by the decubitus, lying down posture ${ }^{9}$ on nasal permeability as well as the effect of nasal breathing problems that some people suffer routinely during sleep. The rest of us experience similar discomfort when we have colds or are forced to spend time in sites with a hot and humid atmosphere. But traditional measurements of nasal resistance do not include these parameters in their protocols.

Thus, the absence of an operating physiological definition of optimal nasal breathing at rest signifies that the hierarchy of the objectives of nasal breathing remains undetermined. What particular characteristic makes the influence of the nasal mucosa so beneficial for inspired air at rest?

\section{2 - DYNAMICS OF INSPIRATION THROUGH A FLEXIBLE NOSE}

In utero above the palatal platform, successive pressure gradients, first negative then positive of amniotic fluid in deforming the wings of the nasal 
capsule, bringing to it the energy needed for activating the morphogenesis of the nasal septa, the turbinate bones, the wings of the nose, and the maxillae $^{33}$ (fig. 1). While under the opposing pressures of the upper lip and the tongue, the contents of the central incisor crypts stimulate the transverse development the premaxillas and the nasal bases of the piriform orifice, by raising the muco-periosteal and facial envelopes. The incompressibility of the enclosed contents of the incisal crypts, which themselves remain deformable, offer a firm support to the bases of the nostrils that, in contrast, the fluctuating fluids of the amniotic fluid had not (fig. 2).

Extra utero the transverse development of the oro-nasal contents of each pre-maxilla continues thanks to the dual stimulation of breathing for the

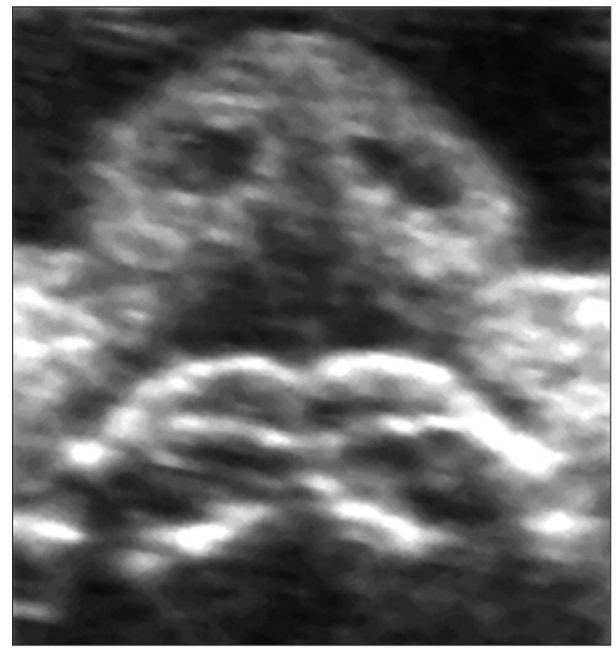

a

Figures 1 a and $b$

a: 27 weeks IU (at left);

b: 32 weeks IU (at right).

These echographic images of the base of the nose and the maxillary central incisor crypts at 27 weeks IU, and left, and 32 weeks IU show that the transverse diameters of the nasal orifices and the diameters of these crypts are about of the same magnitude. (From the records of Dr. Cl. Talmant.) nasal portion and through the growth of the contents of the incisal crypt for the oral portion (fig. 3). The crown sectors of the forming maxillary central incisors remain for a considerable period in contact with the floor of the nose $e^{20}$. But at the beginning of the mixed dentition the eruption of the permanent upper incisors greatly modifies the adjacent support of the nostrils: the incompletely formed roots of these teeth and the osseous septa, that may still be very thin, begin to replace the crowns as bulwarks for nasal growth. The proper unfolding of the local morphogenesis can be adversely affected by a faulty eruptive path of neighboring canines or by labio-nasal skin covering constricting in response to increased nasal resistance caused by nose throat infections

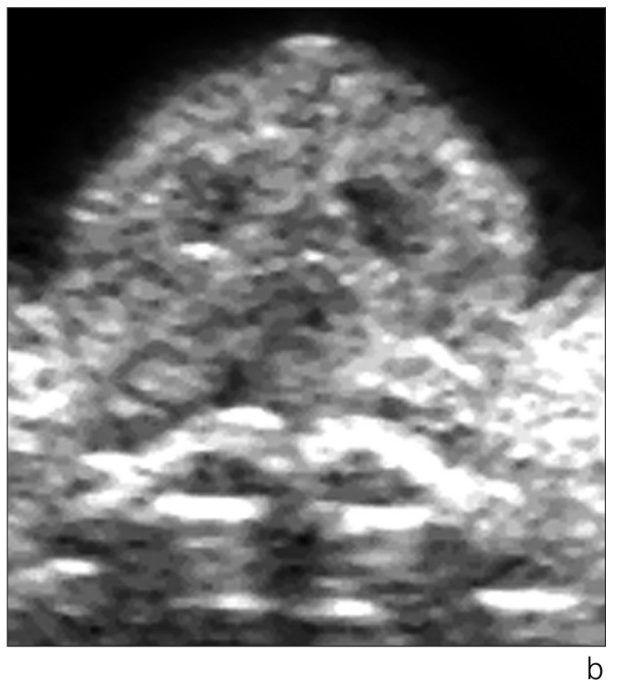



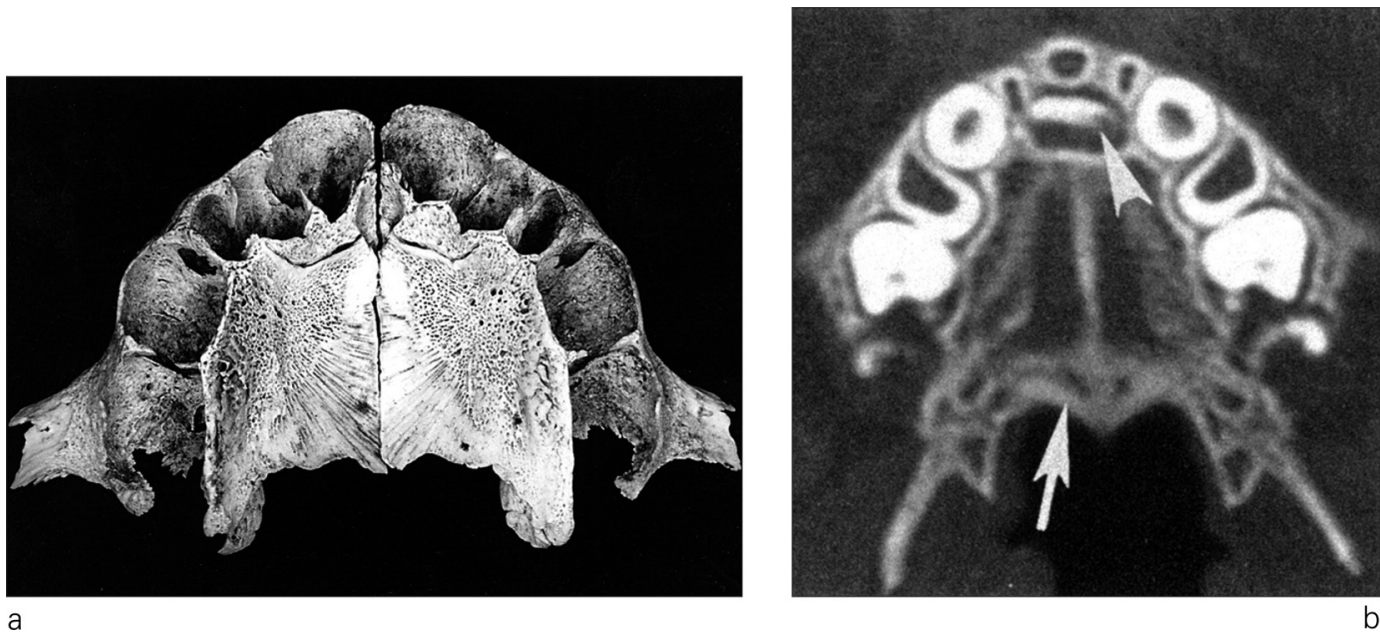

a

Figures $2 a$ and $b$

a: premaxilla of and 8 month IU human fetus (after Thibult ${ }^{37}$ );

b: a single maxillary central incisor occupying the midline region in a nursing infant lafter Belden ${ }^{3}$ ).

During the course of intra-uterine morphogenesis, the expanding contents of the crypts of the temporary and permanent maxillary central incisors oppose themselves to the inspiratory shrinking of the lower part of cartilaginous wings of the nose at the level of the superficial nasal orifices ${ }^{36}$. The inspiratory depression is in effect transmitted directly to the capsular wings by the incompressible amniotic fluid. The buds of the upper central incisors play a truly determining role in the morphogenesis of the nostrils as can be seen in the picture of the solitary symmetrical midline central incisor.

that can lead to compression of the apices of the incisors and canines by the lower parts of the nasal walls thus blocking expansion of the premaxillae and the nostrils (fig. 4). Orthodontists use orthopedic palatal expansion techniques to correct, or better still, to prevent upper anterior crowding and thus restore the transverse labio-nostril support so crucial for dynamic inspiration through a flexible nose and for the postural tonus of the skin covering ${ }^{35}$.

Thus it can be seen that the morphogenesis and the physiological operation of the upper airways depend on both the:

- energetic assistance of nasal regulation, by inspiration then by expiration, of the physical parameters of fluid mobilized by breathing;

- and their relationship with the development of the premaxillary support of the nostrils.

During inspiration, the nose functions like a double convergent-divergent Laval nozzle ${ }^{11}$ with, on each side of the median (fig. 5):

- one convergent: the nostrils;

- one divergent: the nasal fossa;

- one regulating collar: the nasal valve, a portion constricted by several millimeters is situated, going from anterior posteriorly, between the junction of the lateral wing of the nasal cartilage and the head of the lower turbinate bone. 
A dynamic segment of these passages $^{10}$ is:

- stabilized by the bone and the cartilage;

- modulated, as an adjustable collar, by voluntary muscles;

- and regulated by erectile tissue.

When air is seized for inspiration, it is domesticated. In its passage above the upper lip it is inhaled through the nostrils that put it into channels; the dome of the alar cartilage forces it into a right angle turn around the base of the nose, between the nasal floor and the piriform orifice, directing it across the narrowest part of the valve where it accelerates. Electromyography (fig. 6) shows the fluctuations of the dilating action of the wing of the nose as a function of the type of breathing $^{10}$.

The model of the double nozzle progresses from the geometry of the contours of the nasal walls to the dynamics of the fluids flowing through them. During the passage through the collar of one of the Laval ${ }^{29}$ tubes (fig. 7 a) or through a nasal valve ${ }^{5}$ (fig. 7 b): a section regulated nasally, the speed and the pressure of the inspired current of air is subjected to the same types of external, d'extrema, pressure. Thus, just as the skin muscles control the centripetal deformation of inspired air, the valve sections orient the column of air and contribute to the regulation of its acceleration and its drop in pressure. In addition, adjustments in all of these parameters optimize the evaporation of water from the nasal fossas (fig. 8).

The optimal orientation of the current of inspired air toward the middle meatus, which opens into the maxillary sinus, results from the tri-dimensional positioning of the wings of the nose through the action of the skin muscles on the labio-nasal sector of the facial envelope. This action is the
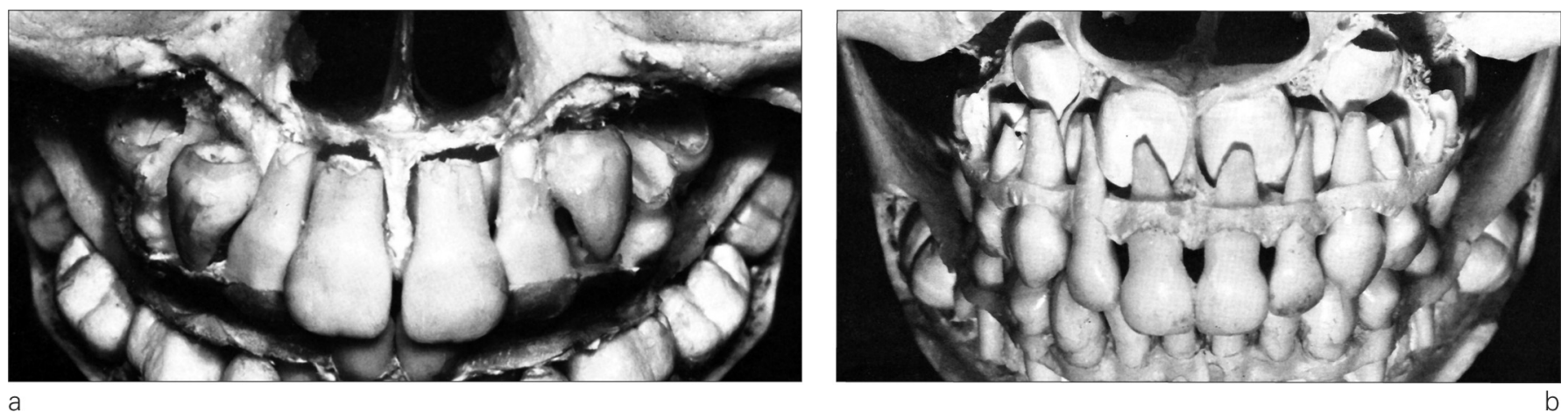

a

Figures $3 a$ and $b$

a: 8 months;

b: 4 years.

Relationship of the contents of the upper incisor dental crypts with the floor of the nose of an 8 month old (left) and right) a 4 year old (after van der Linden and Duterloo ${ }^{39}$ ).

The buds of the maxillary central incisors and their crypts add their power of expansion as a contribution to the transverse development of the base of the nostrils and the piriform orifice. 


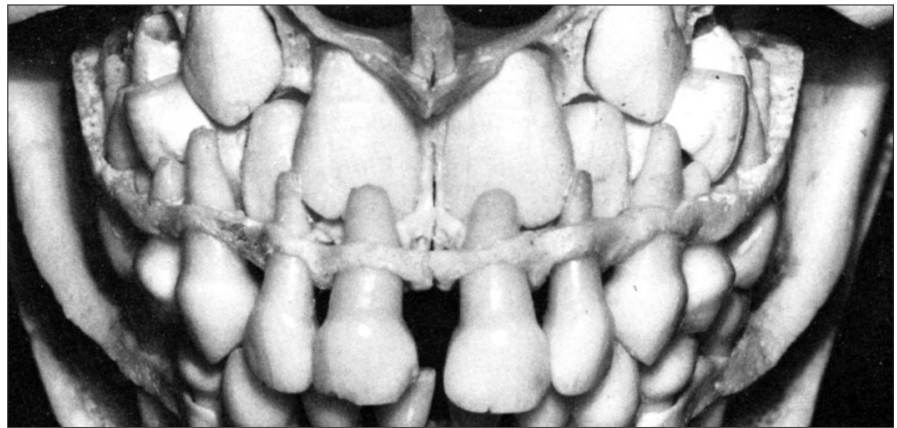

Figures 4 a to $c$

a: 6 years;

b: 8 years;

c: 8 years, with apical compression,

(after van der Linden and Duterloo 39 ).

The eruption of the permanent maxillary incisors represents a critical stage for labio-nasal support and, by extension, for the dynamics of nasal breathing. If a disease process alters nasal mucosa and provoked hypertrophy of pharyngeal lymphoid tissue, the physiological reaction to increased nasal resistance incites an increase in the activity of labio-nasal platysmal skin muscles ${ }^{8}$ which generates compression in the incisal and canine apical areas.

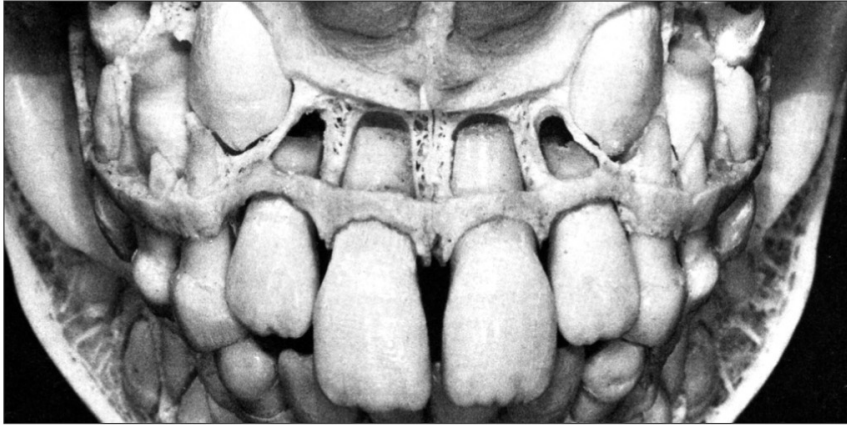

b

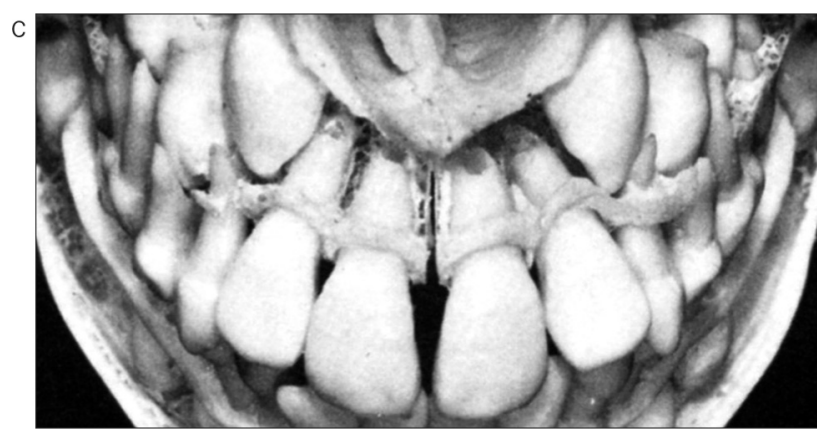

determining factor in achievement of optimal nasal breathing, ONB, and in postural stabilization of facial features (fig. 9). It is also quite likely that the orientation of the current of inspired air plays a role in the eruptive migration of upper permanent canines.

According to the functional objective, the primary current of inspired air can still be directed toward the roof of the nose to be sucked up or toward the base to be sniffled or snorted. To be optimal, nasal breathing at rest depends, in addition, upon a satisfactory character of:
- the morphology of all passages of the nostrils and the nose itself;

- the sensitivity of the cutaneous or mucosal labio-nasal covering (it has been shown in experiments that desensitization of nasal tissues will result in mouth breathing);

- the enervation of labio-nasal skin musculature;

- mucosal secretions and thermal exchanges between inhaled air and blood of the turbinate (nontested elements of the parietal response). 


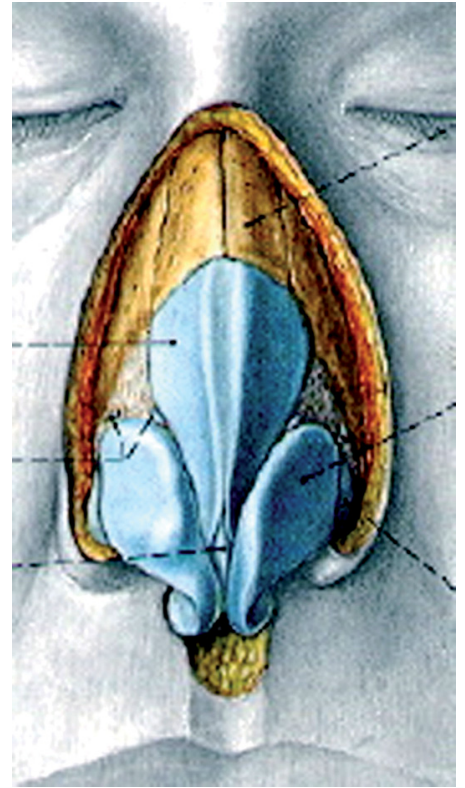

Figure 5

The control of the deformation of the nasal cartilages by the muscles attached to the skin at the level of the lateral alar junction, above the upper border of the alar cartilages, plays a key role in the optimization of the physical parameters of the flow of inspired air (document adapted from Sobotta ${ }^{30}$ ).

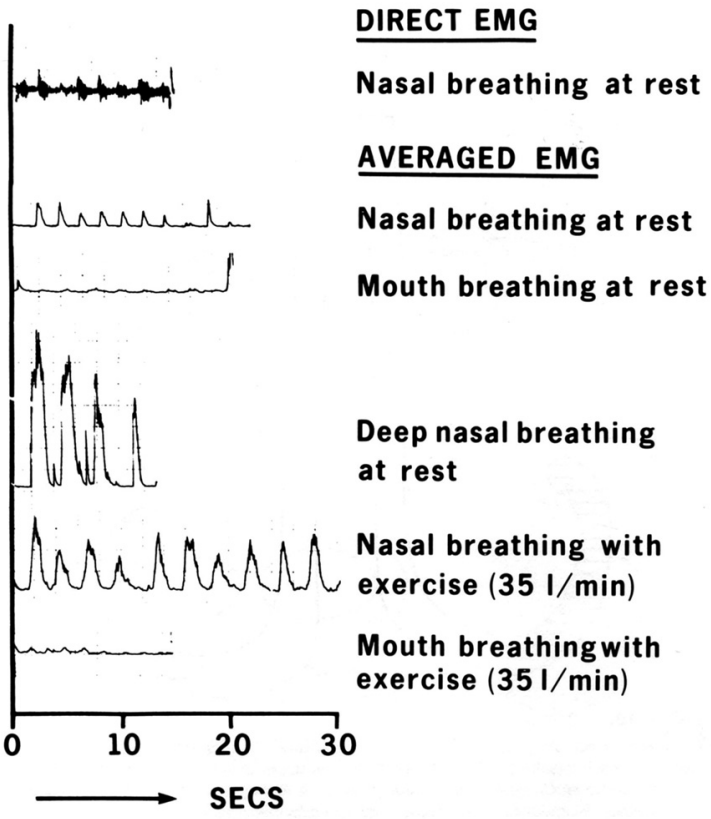

Figure 6

Electromyography shows the dilating action of the latero-alar muscles that increases with the depth of inspiration, stops when mouth breathing takes over or after a tracheotomy (after Cole ${ }^{10}$ ).

\section{3 - THERMAL NASAL EXCHANGE AT THE CHANGE PHASE}

Downstream from the nasal valves, the nasal fossas control thermal exchange during the change phase ${ }^{26}$. In furnishing the calories necessary for the evaporation of a portion of the water contained in the nasal secretions, the turbinal blood incorporates temperature lowering frigories in the nasal fossas. This chilling, which is the equivalent of the heat lost in evaporation, is the fruit of an important quantitative thermal transfer. The temperature variations of the turbinal ${ }^{18}$ mucosa depending on the type of breathing have been evaluated in adults at the level of the inferior turbinate, for a variety of external atmospheric air temperatures, $22 \pm 1{ }^{\circ} \mathrm{C}$ for the following values:

1. The switch from nasal breathing at rest to deep nasal breathing lowers turbinal temperature by 4.62 +/$2.23{ }^{\circ} \mathrm{C}$.

2. Deep nasal inhaling accompanied by exhaling through the mouth, to avoid the exhaled air making the nasal mucosa lukewarm, lowers turbinate temperature from 7.67 $+/-4.2{ }^{\circ} \mathrm{C}$.

3. Changing mouth breathing to at rest nasal breathing raises turbinate 


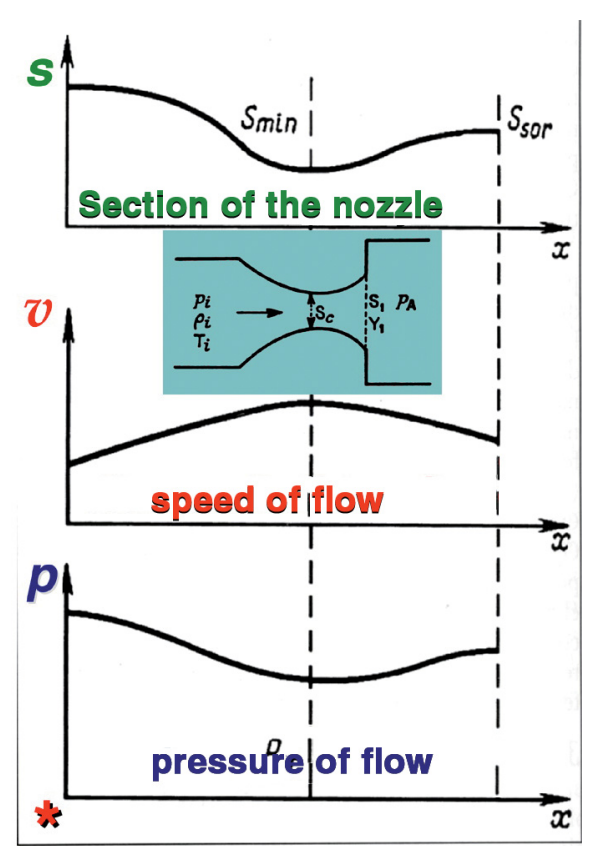

a

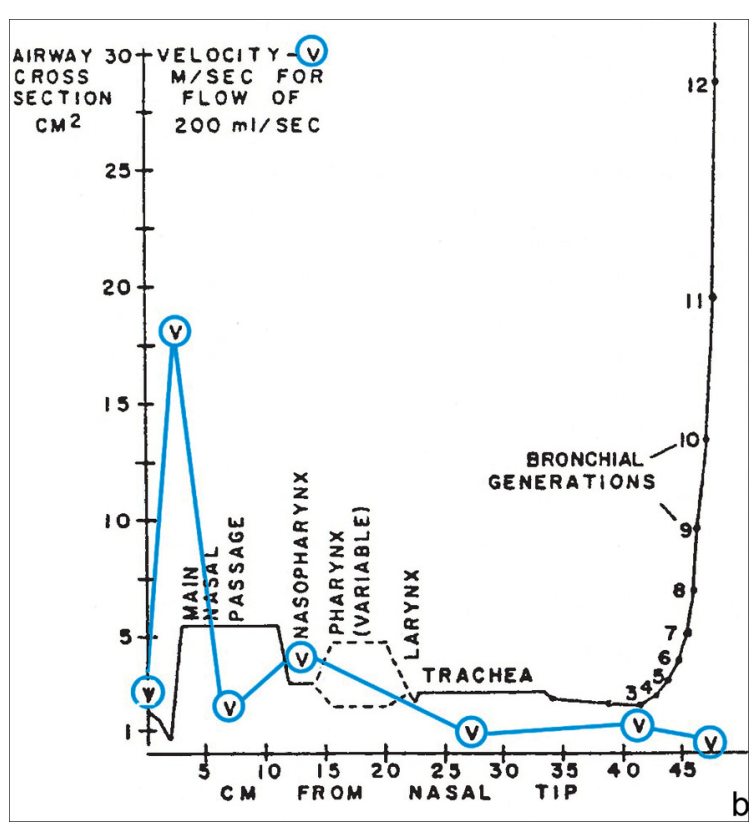

Figures $7 a$ and $b$

a: Schematic section of a convergent-divergent Laval nozzle (after Comolet ${ }^{11}$ ) with:

- upstream space, where the flow has a density of $r$, pressure of $p$, and temperature $T$;

- downstream space, where pressure $P_{A}$ obtains;

- and the collar of section $S_{C}$ connects the convergent and divergent nozzles.

The curves representing the variations of air of the right section, of linear speed and the pressure of the flow along the axis of this type of nozzle (after Sédov ${ }^{29}$ ).

$b$ : Variations of the air in the right section and the speed of flow in the airways in man (after Brain et al. ${ }^{5}$ ).

The mini sketch of the nozzle as well as the valve corresponds to the maximum of the speed of flow and the minimum of its pressure.

temperature from $6.42=+/-$ to $2.83{ }^{\circ} \mathrm{C}$.

4. In deep mouth breathing the temperature of inhaled air in the cervical trachea drops from 4 to $5{ }^{\circ} \mathrm{C}$ below what it would be in at rest nasal breathing, which provokes a reaction in the bronchia in sensitive individuals.

Accordingly, the specific role of the nasal fossas in the treatment of incoming air is to heat it up ${ }^{38}$. When the turbinal and septal sinus tissues are congested, the arterio-capillary network slows the flow of air and enhances the transfer of heat from the mucosa to inhaled air. An important necessity joined to optimum nasal geometry: only with a healthy turbinate mucosa can breathing at rest that is exclusively nasal conduct optimal heat transfers. Evaporation is, therefore, a process of cooling turbinate blood that can flow into the cavernous sinuses. Thus, the bronchial alveoli should not be considered the unique physiological target of 


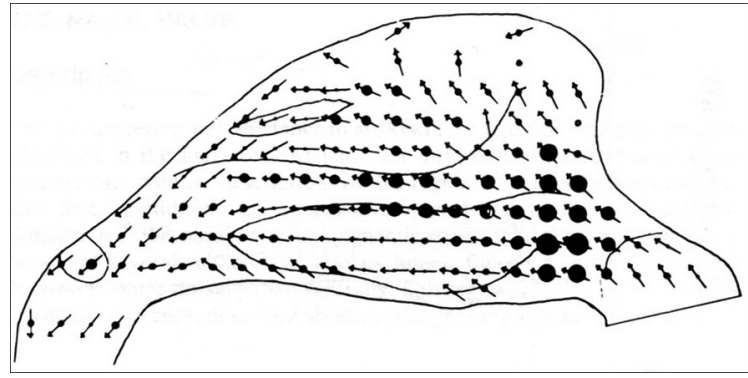

Figure 8

Measurements of the linear speeds and directions of the flow of the current of inspired air. The size of the circles indicates the speed; the arrows show the direction (after Swift et al. $\left.{ }^{31}\right)$. The nasal valves contribute directly to the domestication of the current of inspired air. At its exit from the nasal valves, the current displays its maximum speed, minimal pressure and a preponderant orientation toward the middle meatus.

nasal breathing, something olfaction demonstrates.

In brief, optimal nasal breathing requires a balanced manifestation of physical and biological factors associated with the interaction between air and mucosa. Thanks to the control of the valves exercised by the skin muscles, to healthy nasal mucosal secretion, and to the heat delivered by turbinate blood, the evaporation stimulated by the depression and the orientation of the current of inspired air exiting the nasal valves, produces in the same physical operation:

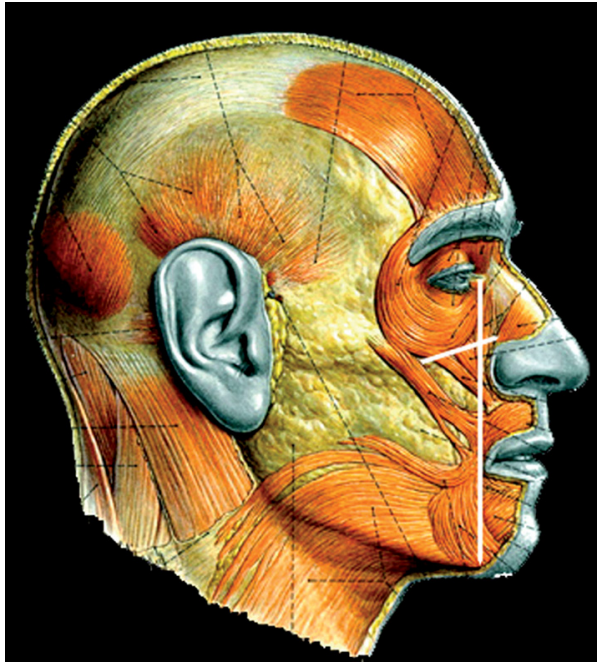

Figure 9

Thanks to the tri-dimensional positioning of the wings of the nose that the skin muscles control, the optimization of the lateral vertical dimension is probably the determining factor for obtaining optimal nasal breathing and the stabilization of the posture of facial features (after Sobotta ${ }^{30}$ ).

- the humid calories destined to reach the bronchial alveoli;

- the corresponding frigories transmitted by the cavernous sinus to structures close to heart of the Central Nervous System (fig. 10).

The functional integration of these transfers confers a profound, but often under-estimated dimension to the thermodynamics of the nasal system the fruit of a frequently altered interaction between inspired air and nasal mucosa.

\section{4 - COUNTERCURRENT HEAT TRANSFER IN THE CAVERNOUS SINUS}

In certain mammals, anatomically Galen's admirable network (rete mirabile) $^{2}$ (fig. 11) is an apparatus that increases the efficiency of thermal exchanges between carotid arterial blood and venous intracavernous venous blood without mixing the flows together. 


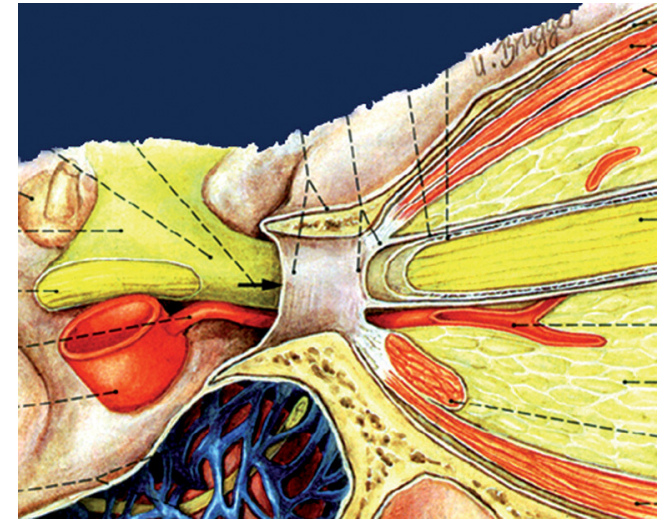

Physically, the human cavernous sinus has the structure of a countercurrent exchanger ${ }^{26}$, in it arterial blood flows in the opposite direction from blood in the veins so that the entering warm arterial fluid passes alongside the exiting cold blood of the veins. The important fact to note in this exchange is that this type of circulation makes heat transfer far more efficient than it

\section{5 - SELECTIVE BRAIN COOLING}

Baker and Hayward ${ }^{1}$ have shown that the admirable network protects the brains of cats and dogs from overheating by selective brain cooling (fig. 12). In 1995, Cabanac ${ }^{7}$ published the first study on selective brain cooling in humans. This process would be especially useful during periods of hyperthermia $^{14}$ :

- for muscles, which are particularly susceptible to deleterious effects of central hyperthermia;

- for the brain, which is also especially vulnerable to the noxious action of hyperthermia.

At rest, cerebral heat regulation is a physiological necessity because me-
Figure 10

The only intra-cranial collateral vessel of the internal carotid artery, the ophthalmic artery emerges from the internal carotid artery usually just after, or in a few cases, just before the latter emerges from the cavernous sinus. For Flalmmer et $a l^{12}{ }^{12}$, the regulation of the ocular sanguinary debit maintains the dorsal pole of the eye at a constant temperature (schematic document after Sobotta ${ }^{30}$ ). Note that the localized cooling originating in the cavernous sinus also affects the pituitary gland and the hypothalamus.

would be if the intracavernous venous and arterial streams of blood moved in the same direction. Researchers discovered the role that the cavernous sinus plays in thermal exchange when they were gathering evidence for the controversial subject of selective brain cooling in humans who have no admirable network.

tabolism of the brain is more exothermic than that of most other tissues.

A study of the variation in the temperature of arterial blood which moves from the aorta to the Willis hexagon eventually to the nasal passages to act on inspired air, to the cavernous sinus, and to the brain, in sleeping cats shows the instructive succession of heat transfers set in action by selective brain cooling ${ }^{2}$.

\section{- During first sleep}

- owing to the nasal vasodilation directed by the autonomic nervous system, evaporation re-heats the inhaled air and simultaneously 


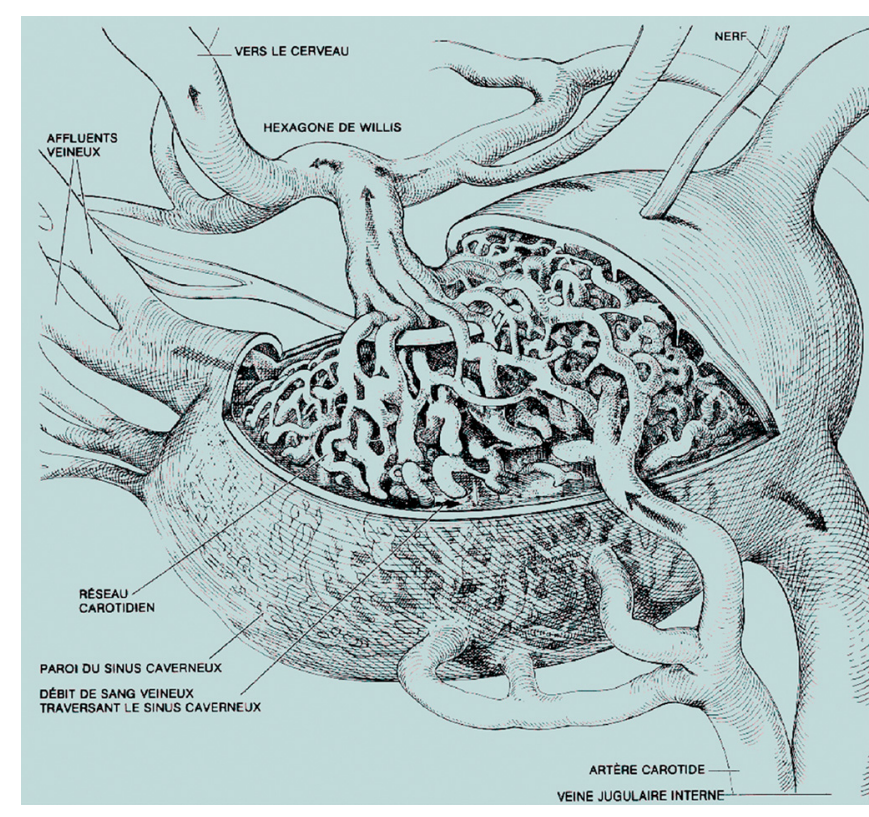

Figure 11

Anatomically, in certain mammals, in its passage through the cavernous sinus, the carotid artery considerably extends its parietal surface by taking the form of Galen's admirable network (rete mirabile) but thinning its walls almost to the thickness of its vascular epithelium (after Baker ${ }^{3}$ ). Some mammals use Galen's "admirable network" as mechanism to accomplish selective brain cooling.

cools the venous turbinate blood that has entered the sinus;

- the carotid blood stream, reaching the temperature of aortal blood in the cavernous sinus, is, in part, cooled as it passes through the Willis hexagon;

- cerebral temperature remains lower than aortic temperature despite the heat its own metabolism produces, a suggestion that selective brain cooling may, in fact, operate in humans.

\section{- During a provoked awakening,}

- autonomic nervous system controlled nasal vasoconstriction

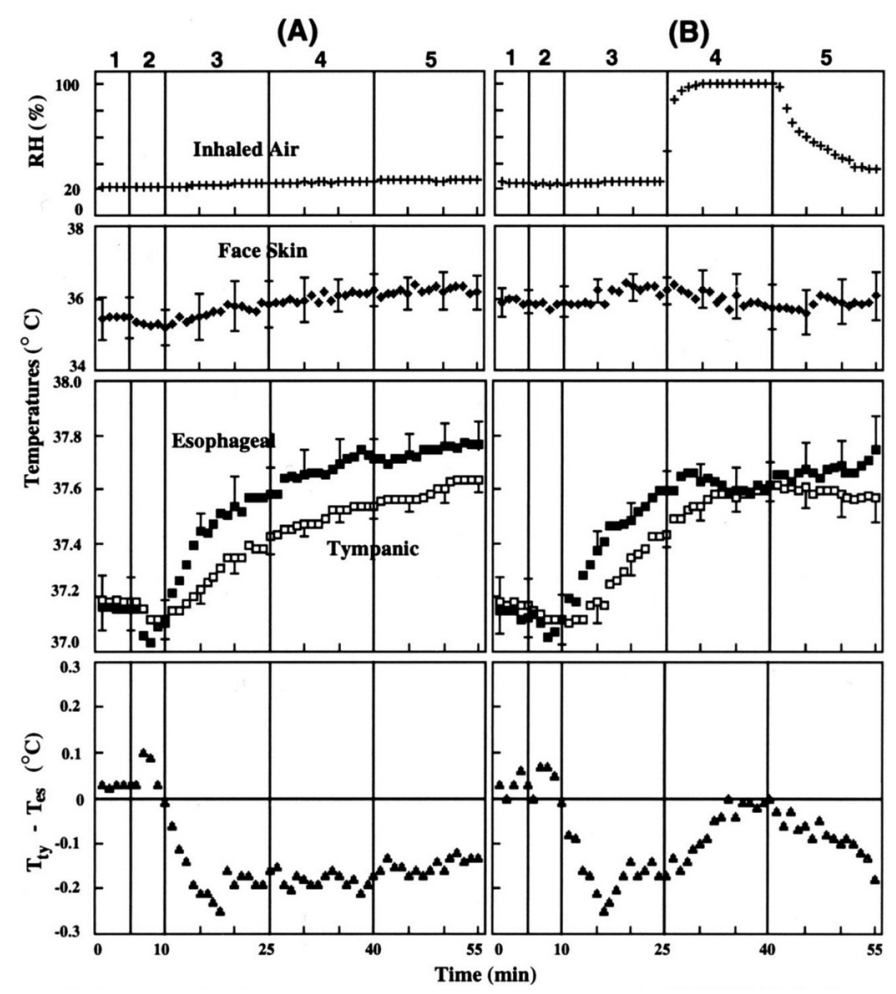

Figure 12

In subjects who have become overheated from muscular exercise, where nasal evaporation no longer operates, inhaling water saturated air stops cavernous cooling and selective brain cooling is not possible. Sweating through the skin takes up the slack in lowering central temperature and, accordingly, the temperature of the esophagus; and the tympanic temperature becomes equal to that of the esophagus (after White and Cabanac ${ }^{43}$ ).

diminishes the reheating of inhaled air, thus also cooling the cavernous sinus;

- the carotid blood stream arrives at the Willis hexagon at the temperature of aortic blood;

- cerebral temperature rises above the aortic temperature.

- As the animal returns to sleep, its different parameters return to the values of its primary sleep.

The human cavernous sinus certainly does not contain a rete mirabile. 
But the length and the extremely diminished walls of the carotid artery as it passes through the cavernous sinus $^{28}$, the proximity and the large size of the sphenoid sinus are anatomic characteristics that would facilitate heat transfer. In the course of neurosurgical procedures ${ }^{23}$ surgeons find that slight chilling of the nasal fossas with moist gas lowers cerebroventricular temperature by $0.2^{\circ} \mathrm{C}$ even the rectal temperature is elevated. Mariak et al. ${ }^{21}$ measured frontal lobe temperature directly just above the cribiform plate during neurosurgical procedures; after extubation, three minutes of deep nasal breathing by the revived patient provoked, on demand, stimulated a local chilling below the esophageal temperature, which corresponds to aortal temperature, that reached $1{ }^{\circ} \mathrm{C}$ per minute, confirming the existence of selective brain cooling provoked by nasal tissues.

Physiologically, the temperature of the tympanic membrane ${ }^{4}$ is a reliable indicator of cerebral temperature. Passive hyperthermia provoked by immersion in a hot bath ${ }^{43}$ causes an inspiratory deficit and hyperpnoea. Because oxygen consumption was the same as the at rest level, there would seem to be no reason for this hyperpnoea. It can be compared to the adjustment achieved by the thermal panting of animals, which participates in their selective brain cooling, the tympanic temperature remaining lower than esophageal temperature for a given debit.

Briefly put, the absence of cerebral quantitative calorimetrics ${ }^{7}$ can no longer be used as an argument disproving the existence of selective brain cooling in humans. And the favorable influence of the therapeutic re-establishment of optimal nasal breathing on selective brain cooling enriches the dossier of the presumptive evidence for the reality of this effect in Homo sapiens.

\section{5 - 1 - The relationship of nasal breathing to sleep}

Sleep is an energy conserving phenomenon ${ }^{17}$ in which the paradoxal phase is the most sensitive to changes in temperature. Accordingly, it can be argued that improperly functioning selective brain cooling is the root cause of numerous sleep disorders ${ }^{13}$ and daily behavioral problems in children and adolescents. The identification and follow-up study of sleep disorders helps, therefore, in the uncovering of nasal malfunctions that manifest themselves clinically in a great variety of forms that are, however, generally similar to those observed in patients with obstructive sleep apnea ${ }^{13}$ and are often identical in the same patient, to wit:

- sleep disturbances, including difficulty in falling asleep, interruptions in sleep with snoring, mouth breathing, cranio-vertical hyperextension, agitation, somnambulism, bed wetting, frequent wake-ups, night sweats, nocturnal anxiety, nightmares, and waking early, but slowly and with difficulty and with the feeling that the night's sleep had not been satisfactory or truly restful;

- problems in waking behavior, including episodes of somnolence, deterioration of ability to memorize data, inability to concentrate, 
problems in school, and headaches on awakening, an ensemble that, when severe, can be characterized as neurosis.

Therefore, an effective treatment of nasal malfunction has the capability of ameliorating all these disorders so long as the mucosal pathology is still reversible.

\section{5 - 2 - The cutaneous origin of selective brain cooling}

Thanks to evaporation of sweat from their scalps marathon runners ${ }^{22}$ can support hyperthermia as high $41.9^{\circ} \mathrm{C}\left(108^{\circ} \mathrm{F}\right)$ when the external temperature is $18.8^{\circ} \mathrm{C}\left(66^{\circ} \mathrm{F}\right)$ without showing any signs of heat stroke. Clinically, care providers can moisten the pillows of sleeping patients to produce a secondary sweating effect when the nasally provoked selective brain cooling action was not working to increase scalp evaporation and thereby chill the cerebrum by reversing the flow of emissary veins ${ }^{6,7}$.

Optimal nasal breathing at rest works better than mouth breathing as a stimulator of selective brain cooling because it conditions the air better and, in so doing, specifically joins in the production of useful frigories. These units work especially well in cooling nervous system structure around the cavernous sinus because they are produced nearby and are scarcely subjected to weakening from ambient heat. So, in effect, by limiting thermal loss in sweating, optimal nasal breathing plays a key part in the body's heat transfers.

\section{5 - 3 - The influence of the nasal cycle on electrocortical activity $^{41,42}$}

The two cerebral hemispheres alternate in dominating each other, a change that is directly correlated with changes in phase of the nasal cycle. When patients are forced to breathe the more physiologically congested nostril, the cerebral hemispheres respond by changing the dominant side, a process that confirms the relationship between optimal nasal breathing and selective brain cooling.

\section{5 - 4 - The effects of orthopedic or surgical treatment on sleep and behavior}

For many years a tonsillectomy, often accompanied by removal of adenoidal tissue, was the treatment of choice for disorders of nasal breathing. Today ENT specialists have largely abandoned the systematic removal of hypertrophied pharyngeal lymphoid tissues because this surgical procedure rarely obtained the anticipated improvement in breathing capacity $^{27}$. Why? Because, in many cases breathing malfunction is caused by a nasal disorder, which itself is the cause of the:

- hypertrophied pharyngeal lymphoid tissues and not the other way around;

- and of a clinically identifiable malfunctioned Oro-nasal malforma$\operatorname{tion}^{34,35}$ (fig. 13).

The interdisciplinary team must devise a treatment plan that will deal with the disorder of the nasal 

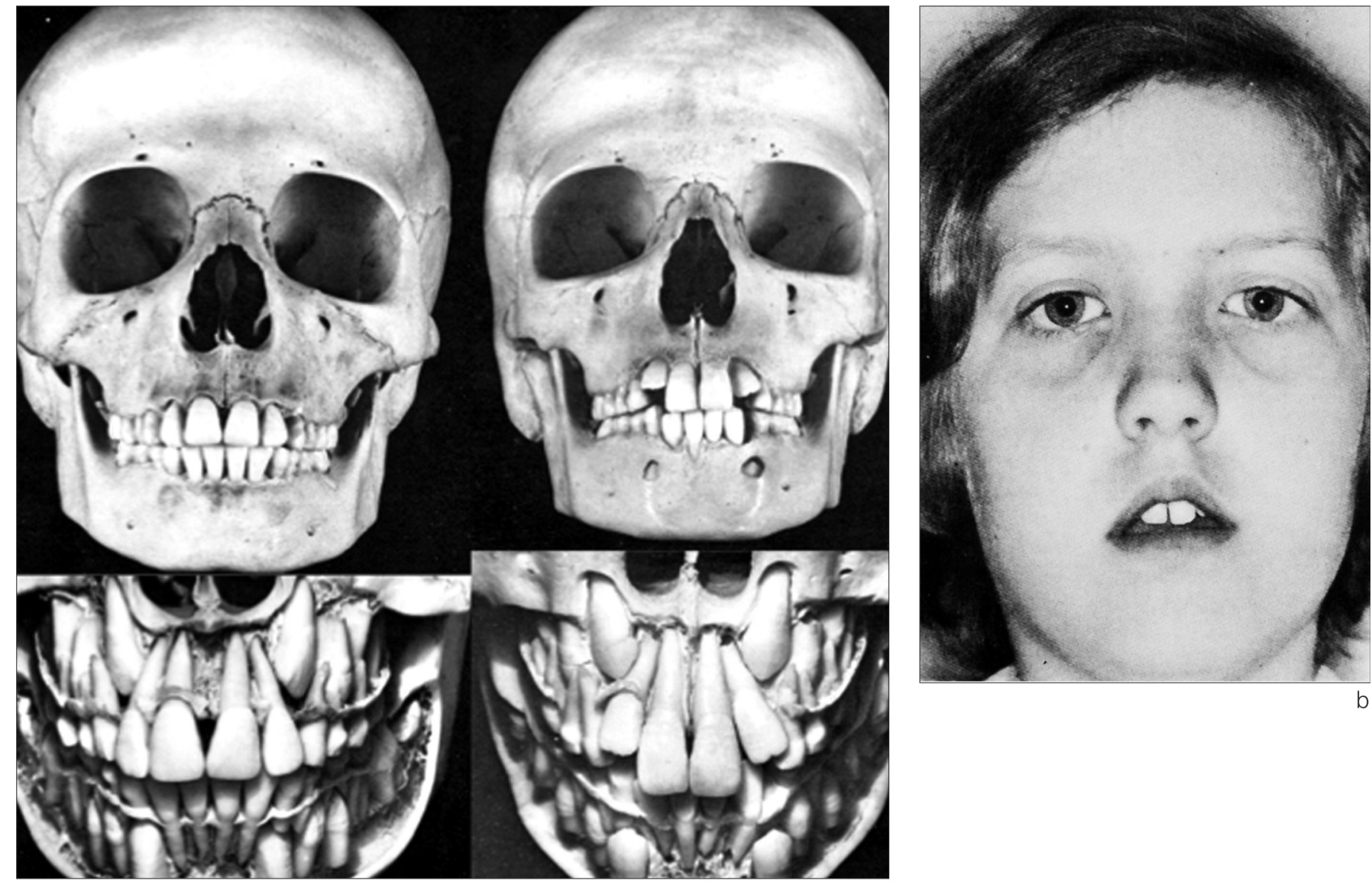

a

Figures 13 a and $b$

a: Some morphological problems amount to more than simple anatomic variations. This is the case with the oro-nasal malformation depicted in the full face view of the girl on the right whose disorder was characterized by insufficiency of the ventral domination of the development of the transverse nasal portion of the piriform orifice, of arch form of both the maxillary and mandibular incisal canine regions. (After van der Linden and Duterloo ${ }^{39}$.)

$b$ : the adenoidal character of the child's face illustrates how nasal obstruction causes postural, labio-nasal, and lower lip and chin adaptations of the facial envelope.

Associated as they are with transverse deficits in the dento-skeletal support as well as with malfunction of the nasal valves, these postural discrepancies are removed when their cause is eliminated (after Linderr-Aronson ${ }^{19}$ ).

mucosa as well as with the skeletal malformations. In correcting the transverse oro-nasal deficits by orthopedic expansion of the premaxilla, in conjunction with complementary medical and/or surgical treatment of the mucosal disorders and with malformations of the septa and/or the turbinate bones, and in remembering that the (non routine) ablation of hypertrophied tonsilar and adenoidal tissue is the province of the otolaryngologist and assuring that the final step in treatment is teaching the patient proper nasal breathing. 
- An immuno-allergological assessment should be a part of the original diagnostic process whenever a patient is suspected of having allergic problems. Allergic desensitization should begin at the same time as the orthodontists begin their treatment. If the allergic care seems unduly extended neither patients nor orthodontists should become discouraged; sometimes lengthy treatment is more effective than treatment begun early and completed quickly.

- Surgical correction of malformed septa or associated turbinate bones may indicate at the close of orthopedic in order to provide otolaryngologists with a more favorable nasal field for obtaining a good surgical result.

After surgery, the orthodontist should put the palatal expansion device back in place to serve as a fixed retainer for the orthopedic movement for as long as it takes for the patient to achieve optimal nasal breathing. It sometimes happens that orthopedic, expansion treatment alone may correct a deviated septum but also unexpectedly cause a return, at least partial, of hypertrophied lymphoid treatment.

\section{- Training patients in correct nasal breathing is the final treatment}

step in helping them to regain vasomotor control of their nasal mucosa. Wearing a two jaw double splint of the positioner type at night at the close of treatment is a useful means of engaging the competence:

- of practitioners in stabilizing the results of their therapy that should help patients attain their goals without discouraging them;

- and of patients in proving they understand the importance of their investment of time and energy to obtain a stable result by keeping the appliance in their mouths throughout nighttime sleep.

Accordingly we can see that the therapeutic effectiveness of expansion of the premaxilla confirms the close relationship between defective nasal breathing and oro-nasal malformations. This success testifies to the morphological and physiological integration of the oral and nasal sectors of the facial envelope. Overly specialized treatment approaches that deal with these two areas separately defy the reality of the shared anatomy and physiology of the neighboring orifices whose conjoined permanent and complementary contributions bear witness to the oro-nasal character of breathing.

\section{6 - AN OPERATIVE PHYSIOLOGICAL DEFINITION OF OPTIMAL NASAL BREATHING AT REST}

The oro-nasal morphology of the face is, accordingly, associated with the fashion in which, at rest, all patients use the mechanics of their facial envelopes $^{32}$ to control the functioning of their nasal valves, taking into account the capacities of the heat transfers of their nasal mucosa. The morphological response $^{15,19,35}$ to the physiological demands to which the face must incessantly respond are, in the final analysis, the fruit of the postural control 
exercised by the skin muscles of the oral and nasal openings in the facial envelope. Treatment should be directed toward the goal of restoring optimal nasal breathing, which, in turn, will improve facial posture.

When during the growth period, malformations of the anterior incisor and canine sector of the dental arch appear, orthodontic treatment should aim not only at correcting the malalignment of the teeth but also at the transverse deficit of the premaxilla which serves jointly as the roof of the mouth and the floor of the nose. Expansion of this structure can not only help align teeth but also correct malfunction of nasal breathing at rest, whose re-establishment is a therapeutic objective more beneficial than simple normalization of nasal resistance and orthstatism.

Finally, here is a physiological definition of optimal nasal breathing $^{\text {34: }}$ it is "breathing at rest that is spontaneously and exclusively nasal during the day and at night, in decubitus during sleep." Operatively, this physiological definition fixes the criter-

\section{7 - CONCLUSION}

Breathing at rest mobilizes two types of heat exchanges. The dynamics of the thorax container transmit to the volume of air it contains a kinetic energy needed to assure the renewal and hydrous as well as thermal conditioning of the upper airways through which it will pass. The most effective heating of inspired air takes place during nasal breathing ${ }^{10}$. This increase in temperature decreases the conditioning work load of the trachea and the ia for clinical diagnosis, marking the part properly assigned to the mucosa in dysfunctional breathing: the character of sleep, behavior during the day, and the postural adaptations of the cervico-cephalic and facial soft tissues to which must be added the manifestations of obstructions in the upper airways, as observed clinically and radiographically as well as through rhinomanometrics. Why should so much be demanded of Optimal Nasal Breathing at rest during sleep?

- Because the circulatory system provokes nasal congestion when patients are lying down making optimal nasal breathing more demanding in producing frigories;

- because the demands for selective brain cooling at rest increase during certain sleep periods;

- and because the peak flow of growth hormone secretion occurs during the first part of the nocturnal sleep period. (An increase in growth just after eruption of the maxillary incisors may be an indicator of an improvement in the action of selective brain cooling.)

bronchial tubes. It also assists the chilling of venous blood in the turbinate bones, a component selective brain cooling, which reduces the energy output required for sweating while it simultaneously protects sleep, another energy demanding phenomenon. In optimizing the global performances of breathing at rest with respect to the energy invested the savings it achieves earn Nasal breathing at rest the distinction of being described as 
“Optimal." Its positive contribution to intracranial thermal regulation also clearly distinguishes it from mouth breathing.

Therefore, we can safely say that the Medical and Surgical specialists, orthodontists among them, have already proved they can intervene at the appropriate moment to correct defor- mities and thereby provide their patients with a pathway to optimum oro-nasal functioning and good facial posture. But they have demonstrated even more. Inter-disciplinary teams of physicians and dentists can, in the future, achieve goals even more beneficial than the ones that are currently assigned to them.

\section{REFERENCES}

1. Baker MA, Hayward JN. Carotide rete and brain temperature of cat. Nature 1967;216: 13941.

2. Baker MA. La thermorégulation du cerveau des mammifères. Pour la Science 1979;21: 8391.

3. Belden CJ, Mancuso AA, Schmalfuss IM. CT features of congenital nasal piriform aperture stenosis : initial experience. Radiology 1999;213:495501.

4. Bezinger TH, Taylor GW. Cranial measurements of internal temperature in man. In : Temperature: its measurement and control in science and industry. Hardy JD. New York: Reinhold 1963:11120.

5. Brain et al. Respiratory defense mechanisms. In: Lenfant C.(éd.) Lung biology in health and disease. New York: M. Decker, 1977.

6. Cabanac M, G. Perrin, M. Caputa. Ecoulement sanguin réversible dans la veine ophtalmique : Mécanisme de refroidissement sélectif du cerveau humain. C.R.Acad. Sci. Paris 1978;87D:10114.

7. Cabanac M. Human selective brain cooling. New York: Springer Verlag, 1995.

8. CastelCorlay A, Chrétien N, Cuny M, Deniaud J. Étude des variations de l'activité musculaire des peauciers de la face au cours du traitement des insuffisances transversales maxillaires par quadhélix. Rev Orthop Dento Faciale 2009;43(4):4716.

9. Cole P, Haight JSJ. Posture and nasal patency. Am Rev Respir Dis 1984;129:3514.

10. Cole P. The respiratory role of the upper airways. St Louis: Mosby Year Book, 1993.

11. Comolet R. Mécanique expérimentales des fluides. Paris: Masson, 1979.

12. Flammer J, Mozaffarieh M. Autoregulation, a balancing act between supply and demand. Can J Ophthalmol 2008;43:31721.

13. Guilleminault C, Quo S, Huynh NT, Li K. Orthodontic expansion treatment and adenotonsillectomy in the treatment of obstructive sleep apnea in prepubertal children. Sleep 2008;31(7):9537.

14. Hales JRS. Effects of exposure to hot environnements on total and regional blood flow in the brain and spinal cord of the sheep. Pflügers Arch 1973;344:32737.

15. Harvold EP, Tomer BS, Chierici G. Primate experiments on oral respiration. Am J Orthod 1981;79:35972.

16. Jacrot B. Conclusion. In : Jacrot B, Pebay Peyroula E, Mache R, Debru Cl. Physique et biologie. Une interdisciplinarité complexe. Paris : EDP Sciences, 2006:119121.

17. Jouvet M. Le sommeil et le rêve. Paris : Odile Jacob, 1992.

18. Konno et al. Upper Airway Mucosa as an Air Conditioner. O R L, 1985.

19. LinderAronson S. Nasorespiratory function and craniofacial growth. In McNamara JA $J R$, éd. Nasorespiratory function and craniofacial growth. Vol 9, Craniofacial Growth Series. Ann Arbor : Center for Human Growth and Development, University of Michigan, 1979:12147. 
20. Marc F. Étude par scanographie à rayons $X$ des corrélations entre la largeur des incisives maxillaires et les dimensions transversales de l'orifice piriforme. Mémoire de certificat d'études cliniques spéciales mention orthodontie. NANTES : Univ Nantes, 2005.

21. Mariak Z, White MD, Lewko J, Lyson T, Pickarski P. Direct cooling of the human brain by heat loss from the upper respiratory tract. J Appl Physiol 1999;87(5):160913.

22. Maron MB, Wagner JA, Horvath SM. Thermoregulatory responses during competitive marathon running. J App Physiol 1977;42:90914.

23. Mellergaard $P$. Changes in human intracerebral temperature in response to different methods of brain cooling. Neurosurgery 1992;31:6717.

24. Naito K, Cole $P$, Chaban $R$, et al. Nasal resistance, sensation of obstruction and rhinoscopic findings compared. Am J Rhinol 1988;2(2):6569.

25. Niiminaa V, Cole P, Mintz S. et al. Oronasal distribution of respiratory airflow. Respir Physiol 1981;43:6975.

26. Padet J. Echangeurs thermiques. Paris: Masson, 1994.

27. Praud JP, Dorion D. Obstructive sleep disordered breathing in children : beyond adenotonsillectomy. Pediatr Pulmonol 2008;43:837-43.

28. Rouvière H. Anatomie humaine descriptive et topographique. Paris: Masson, 1962:196.

29. Sédov L. Mécanique des fluides. Moscou : Mir, 1975.

30. Sobotta. Atlas d'anatomie humaine. Putz R, Pabst R. (éds.). Cachan : ÉMI, 1994.

31. Swift DL, Proctor DF. : Access of air to the respiratory tract. In Brain JD, Proctor DF, Reid LM (eds): Respiratory defense mechanisms. New York, Marcel Dekker, 1977:80.

32. Talmant J, Talmant JC, Deniaud J. Mécanique de l'enveloppe faciale. 2 Fente orale et concentration des contraintes (aspects fondamentaux). Rev Orthop Dento Faciale 1999; 33:21132.

33. Talmant J, Deniaud J, Nivet MH. Ventilation fœtale, ventilation postnatale et morphogenèse. In : La dimension verticale. 1 Ventilation nasale et dimension verticale: bases morphologiques et physiologiques. Orthod Fr 2003;74(2):147200.

34. Talmant J, Deniaud J, Nivet MH. Définition de la "ventilation nasale optimale». In : La dimension verticale. 1 Ventilation nasale et dimension verticale : bases morphologiques et physiologiques. Orthod $\operatorname{Fr} 2003 ; 74(2): 20125$.

35. Talmant J, Deniaud J, Nivet MH. Mécanismes posturaux. In : La dimension verticale. 1 Ventilation nasale et dimension verticale : bases morphologiques et physiologiques. Orthod Fr 2003;74(2):22783.

36. Talmant J, Deniaud J. Du rôle des incisives maxillaires dans le développement de la base du nez. Applications en orthopédie dentofaciale. Orthod Fr 2006;77:1962.

37. Thibult JL. Contribution à l'étude du Prémaxillaire. Thèse Odontologie $3^{\mathrm{e}}$ Cycle. Nantes: Univ. de Nantes, 1978.

38. Uziel A, Guerrier Y. Physiologie des voies aérodigestives supérieures. Paris: Masson, 1984.

39. van der Linden FPGM, Duterloo HM. Development of the human dentition. An Atlas. Hagerstown, Maryland: Harpers \& Row, 1976.

40. Warren DW, Drake AF, Davis JU. The nasal airway in breathing and speech. In : Berkovitz S, (éd.), Cleft lip and palate. Perspectives in management. Vol 2. San Diego: Singular Publishing Group Inc, 1996:6173.

41. Werntz DA, Bickford RG, Bloom FE. et al. Alternating cerebral hemispheric activity and the lateralization of autonomic nervous function. Human neurobiol 1983;2:3943.

42. Werntz DA, Bickford RJ, ShannahoffKhalsa DS. Selective hemispheric stimulation by unilateral forced nostril breathing. Human neurobiol 1987;6:16571.

43. White MD et Cabanac M. In : Cabanac M. Human selective brain cooling. New York: Springer Verlag, 1995.

44. White MD, Cabanac M. Nasal mucosal vasodilatation in response to passive hyperthermia in humans. Eur J Appl Physiol 1995;70:20712. 